\title{
Una reseña de Language in Children
}

\section{A review of Language in Children}

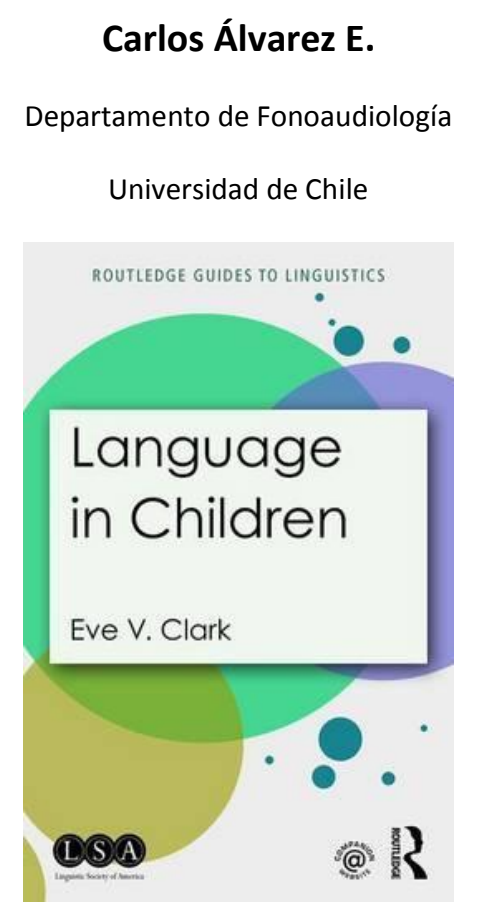

Autora: Eve V. Clark

Editorial: Routledge Guides to Linguistics

Número de páginas: 172 páginas

Año: 2016

ISBN: 1138906077

Datos de la autora: Eve Clark, académica del Departamento de Lingüística de Stanford University, Estados Unidos.

El desarrollo del lenguaje en los seres humanos es un fenómeno que por décadas ha atraído la atención de investigadores de las más diversas disciplinas académicas. Sin embargo, no solo la comunidad científica se ve interesada por hitos como la emergencia espontánea de las primeras palabras y posteriores construcciones sintácticas de un niño, sino que el interés es compartido por la mayoría de los miembros de la sociedad. No todos los fenómenos humanos cuentan con obras que describan sus principales 
características con lucidez y profundidad. El lenguaje humano y su desarrollo, sí. En este sentido, Language in Children, primer libro de la serie Routledge Guides to Linguistics, constituye un valioso aporte a la consolidación de un cuerpo de conocimiento en cuya construcción la autora Eve V. Clark ha jugado un rol preponderante.

Language in Children, editado en conjunto por la Sociedad Norteamericana de Lingüística (LSA, por sus siglas en inglés) y la editorial Routledge entrega a lectores, tanto expertos como no expertos en el tema, una clara caracterización del desarrollo del lenguaje en niños, enfatizando la importancia que tienen en este proceso aspectos sociales como la interacción entre niños y adultos. Así, ya en el prefacio de la obra, la autora destaca que los niños desde temprana edad atienden a las emisiones lingüísticas de los adultos, reciben retroalimentación de estos y ponen en práctica lo adquirido en la serie de intercambios comunicativos diarios en los que participan activamente.

Eve V. Clark organiza su obra en 10 capítulos temáticos. En cada uno de ellos, al igual que en sus publicaciones previas, la autora entrega al lector información con una sólida base empírica ilustrada con muestras auténticas de lenguaje. Un importante acierto en este aspecto es la variedad de lenguas en que se presentan los ejemplos. Es posible encontrar muestras de lenguaje en español, francés, portugués e inglés. En efecto, la entrega de ejemplos en diferentes lenguas hace de Language in Children un obra que establece que las etapas del desarrollo del lenguaje en los seres humanos son, en gran medida, universales en condiciones psicológicas, biológicas y sociales típicas.

Ante todo, de Language in Children hay que destacar que en cada capítulo la autora menciona una serie de principios generales que guían el desarrollo de los diferentes ámbitos que componen las lenguas naturales. Al respecto, uno de los primeros principios presentados da cuenta de la heterogeneidad, en términos temporales, en el proceso de adquisición: los seres humanos adquieren aspectos de su lengua materna tales como morfemas flexivos o palabras funcionales en diferente ritmo. Según la autora, pueden haber diferencias de hasta un año en niños con desarrollo típico que están adquiriendo un aspecto en particular de una misma lengua. Por otro lado, estas diferencias también serían evidentes cuando dos niños están adquiriendo, por ejemplo, la morfología flexiva de pluralización de sus respectivas y distintas lenguas materna. De este modo, un niño cuya lengua materna es el inglés habrá dominado el sistema de pluralización entre los 3 y 4 años de edad, en tanto que un niño cuya lengua materna es el árabe lograría un dominio de dicho aspecto morfológico, aproximadamente, a los 12 años la edad. En este caso, las propiedades morfológicas de cada lengua inciden en los ritmos de adquisición. Un segundo principio por destacar tiene que ver con la relación existente entre la complejidad de las ideas que posee un niño y la complejidad de las construcciones que ha adquirido en su lengua materna. La autora establece que, a medida que los niños van creciendo en edad, sienten mayor necesidad de expresar ideas cada vez más complejas. Para esto, no cabe duda que es indispensable contar con construcciones de mayor complejidad 
que permitan la expresión de dichas ideas. Es así como el desarrollo cognitivo de un niño está estrechamente relacionado con su desarrollo lingüístico. Un tercer principio tiene que ver con la disminución gradual de la orientación lingüística que brindan los adultos a los niños cuando estos últimos ya han adquirido ciertos niveles de dominio general en su lengua materna. Así, por ejemplo, un adulto entregará cada vez menos retroalimentación a un niño en términos de adecuación lingüística contextual debido a que, con el paso de los años, estos logran distinguir y manejar diferentes registros dependiendo de las características de su interlocutor.

Sin duda alguna, lo más destacable de Language in Children es el dinamismo y profundidad informativa que cada capítulo ofrece. Por tanto, se constituye como una obra que, en su totalidad, cautiva y sorprende al lector. Eve V. Clark cumple ampliamente su propósito de ofrecer una introducción general al desarrollo del lenguaje en niños y promover la realización de estudios que den cuenta de aquellos aspectos de los cuales aún se cuenta con escasa información. Las características antes señaladas hacen de Language in Children una obra ampliamente recomendable para estudiantes de programas de pregrado en Fonoaudiología y Educación Parvularia. Así mismo, Language in Children es una fuente confiable de consulta de información académica para profesionales de los ámbitos del lenguaje y la comunicación en niños. 